\title{
Additional prognostic value of toe-brachial index beyond ankle-brachial index in hemodialysis patients
}

\author{
Manabu Hishida ${ }^{1,2}$, Takahiro Imaizumi ${ }^{2}$, Steven Menez ${ }^{1,3}$, Masaki Okazaki ${ }^{2}$, Shin'ichi Akiyama ${ }^{2}$, Hirotake Kasuga ${ }^{4}$, \\ Junichi Ishigami ${ }^{1}$, Shoichi Maruyama ${ }^{2}$ and Kunihiro Matsushita ${ }^{*^{*}}$ (D)
}

\begin{abstract}
Background: Ankle-brachial index (ABI), the first-line diagnostic test for peripheral artery disease, can be falsely elevated when ankle arteries are incompressible, showing a J-shaped association with mortality. In this situation, toe-brachial index (TBI) is the recommended test. However, whether TBI provides additional prognostic information beyond $\mathrm{ABI}$ in patients on hemodialysis is unknown.

Methods: In this retrospective cohort study of 247 Japanese prevalent hemodialysis patients (mean age 66.8 [SD 11.6] years), we evaluated mortality (116 deaths over a median follow-up of 5.2 years) related to quartiles of $A B I$ and $\mathrm{TBI}$, as well as three categories of low $\mathrm{ABI}(\leq 0.9)$, normal/high $\mathrm{ABI}(>0.9)+$ low TBI $(\leq 0.6)$, and normal/high $\mathrm{ABI}+$ normal TBI (>0.6) using multivariable Cox models.

Results: $\mathrm{ABI}$ showed a J-shaped association with mortality (adjusted hazard ratio 2.72 [95\% Cl, 1.52-4.88] in the lowest quartile and 1.59 [95\% Cl, 0.87-2.90] in the highest quartile vs. the second highest). Lower TBI showed a potentially dose-response association with mortality (e.g., adjusted hazard ratios 2.63 [95\% Cl, 1.36-5.12] and 2.89 $[95 \% \mathrm{Cl}, 1.49-5.61]$ in the lowest two quartiles vs. the highest). When three categories by both $\mathrm{ABI}$ and TBI were analyzed, those with low ABI $(\leq 0.9)$ experienced the highest risk followed by normal/high $\mathrm{ABI}(>0.9)+$ low TBI $(\leq 0.6)$. Among patients with normal/high $\mathrm{ABI}(>0.9)$, the increased mortality risk in individuals with low TBI $(\leq 0.6)$ compared to those with normal TBI (>0.6) were significant (adjusted hazard ratio 1.84 [95\% Cl, 1.12-3.02]).

Conclusions: Lower TBI was independently associated with mortality in patients on hemodialysis and has the potential to classify mortality risk in patients with normal/high ABI. Our results support the importance of evaluating $T B I$ in addition to $A B I$ in this clinical population.
\end{abstract}

Keywords: Hemodialysis, Peripheral artery disease, Mortality, Ankle brachial index, Toe brachial index

\section{Background}

Lower-extremity peripheral artery disease (PAD) is recognized as a major risk factor for amputation, myocardial infarction, and stroke [1,2]. Patients with chronic kidney disease (CKD) are prone to developing

\footnotetext{
*Correspondence: kmatsus5@jhmi.edu

'Department of Epidemiology, Johns Hopkins Bloomberg School of Public Health, 2024 E. Monument Street, Suite 2-600, Baltimore, MD 21287, USA Full list of author information is available at the end of the article
}

PAD [3-5]. This is especially true in patients on hemodialysis. Indeed, the incidence of PAD is higher than that of myocardial infarction or stroke in this clinical population [6].

Major guidelines recommend the ankle-brachial index $(\mathrm{ABI})$ as the first-line non-invasive diagnostic test for $\operatorname{PAD}[2,7,8]$. However, ABI may be falsely high in individuals with calcified ankle arteries $[9,10]$. Indeed, previous studies demonstrated a J-shaped association 
between $\mathrm{ABI}$ and mortality (i.e., elevated risk in both lower and higher $\mathrm{ABI})[11,12]$, which may complicate the interpretation of $\mathrm{ABI}$, especially in individiuals prone to vascular calcification like patients on hemodialysis and diabetes mellitus [9, 10, 13-15].

To overcome this caveat of $\mathrm{ABI}$, clinical guidelines recommend using toe-brachial index (TBI) when $\mathrm{ABI}$ is greater than 1.4, since toe arteries are less likely to be calcified [16, 17]. Importantly, a few studies have reported that TBI provides additional or even better prognostic information than $\mathrm{ABI}$ in persons with diabetes [18] and CKD [19]. A similar result was recently reported among patients on hemodialysis [20]. However, this study included only 37 patients, and thus a larger comprehensive study is necessary.

Therefore, we sought to quantify and contrast the association of $\mathrm{ABI}$ and TBI with mortality in patients on hemodialysis. Additionally, we assessed whether TBI values could distinguish the risk of mortality in patients with normal/high ABI.

\section{Materials and methods Study participants}

We conducted a retrospective cohort study using data from Kaikoukai Central Clinic, which is one of several Kaikoukai Healthcare Group outpatient hemodialysis facilities in Japan. Between April 2009 and July 2015 (baseline period), we identified 659 consecutive patients aged 20 years or older who received maintenance hemodialysis therapy. For the current study, we investigated 247 prevalent hemodialysis patients with data on both ABI and TBI measurements prior to the baseline date described below (Supplementary File: Fig. S1). Patients excluded from this study had generally similar characteristics to the study population in terms of age, gender, and the prevalence of hypertension. The major differences were seen in hemodialysis vintage, a history of cardiovascular disease (CVD), and primary kidney disease (Supplementary File: Table S1).

\section{Baseline variables}

For patients who were already receiving hemodialysis at this clinic at the start of the baseline period, the baseline date for observation was set to April 1st, $2009(n=239)$. For those patients who were referred to this clinic for hemodialysis maintenance during the baseline period, the baseline date was set to the day of referral $(n=8)$. Age, gender, hemodialysis vintage, smoking status, primary kidney disease, history of PAD and other CVD (coronary artery disease, heart failure, and stroke), other medical comorbidities, and home medications at the baseline were systematically abstracted from medical records.
We used laboratory data collected most closely to the baseline, at a median of 6 (inter quartile interval [IQI] 5-12]) days after baseline. For those who had a hemodialysis vintage of $<3$ months at baseline $(n=2)$, we used blood tests collected three months after hemodialysis initiation. This approach was based on the fact that laboratory variables might be unstable in the first few months after hemodialysis initiation, as previously reported [21, 22].

The ABI and TBI measurements were performed according to clinical indications (e.g., intermittent claudication and coldness of feet). ABI and TBI were obtained at any time during a patient's hemodialysis session in a room maintained at a temperature between 26 and $27^{\circ} \mathrm{C}$, using a non-invasive oscillometric device (BP203RPE III system [OMRON HEALTHCARE Co., Ltd., Kyoto, Japan]), with the patient in the supine position. Blood pressure cuffs were placed on the arm without the arteriovenous fistula or graft, on the ankles, and at the bases of the big toes. ABI and TBI were determined as the ratio of ankle systolic blood pressure and toe systolic blood pressure to brachial systolic blood pressure, respectively. ABI and TBI were measured bilaterally on the same day, and the lower values of right and left $A B I$ and TBI were used for the analysis.

\section{Outcomes}

The primary outcome was all-cause mortality, and we also secondarily investigated CVD mortality and nonCVD mortality, separately. CVD mortality was defined as death due to coronary artery disease, stroke, heart failure, aortic disease, or sudden cardiac death. Outcome data were available as long as the patients were followed within the Kaikoukai Healthcare Group. Patients were followed until death $(n=116)$, loss to follow-up $(n=30)$, or the end of follow-up $(n=101)$ on 31 March 2016 (i.e., administrative censoring).

\section{Statistical analysis}

Baseline characteristics were expressed as mean (SD) or number (percentage). One-way ANOVA with post-hoc Tukey test was used to compare the characteristics across TBI quartiles. We first estimated survival across ABI and TBI quartiles using the Kaplan-Meier method and assessed the difference in survival estimates by the log-rank test.

For the primary analysis, we imputed missing data on some covariates (i.e., systolic blood pressure [missing in $n=2]$, diabetes mellitus $[n=6]$, calcium $[n=8]$, phosphate $[\mathrm{n}=8]$, total cholesterol $[n=29]$, hemoglobin $[n=$ 23], albumin [ $n=34]$, and smoking status $[n=35]$ ) using multiple imputation by chained equations. In brief, missing values were imputed and regressed on all variables in the analysis, including outcome variables. Each 
imputation was conducted by logistic regression for binary variables, and by linear regression for continuous variables. This procedure was then repeated 25 times to construct a pooled dataset [23].

Using the imputed data set, multivariable Cox models were conducted to estimate the hazard ratios (HRs) of all-cause mortality, CVD mortality, and non-CVD mortality by $\mathrm{ABI}$ and $\mathrm{TBI}$ quartiles. We explored four models: Model 1 was unadjusted; Model 2 adjusted for age and gender; Model 3 additionally adjusted for a clinical history of diabetes, smoking status, CVD history (PAD and other CVD), and hemodialysis vintage; and Model 4 further adjusted for systolic blood pressure, total cholesterol, hemoglobin, serum albumin, serum calcium, and serum phosphate. We selected the second highest quartile of $\mathrm{ABI}$ and the highest quartile of $\mathrm{TBI}$ as a reference based on their respective J-shaped and linear relationships to mortality from previous literature $[11,12,18]$. P for trend was calculated in the lowest three quartiles for ABI (due to its J-shaped association) and in all quartiles for TBI by modeling them as continuous variables.

Subsequently, we assessed the mortality risk across categories using combinations of ABI and TBI. Since there were few patients with low ABI but normal TBI, we investigated the following three categories: Low $\mathrm{ABI}$, normal/high $\mathrm{ABI}+$ low $\mathrm{TBI}$, and normal/high $\mathrm{ABI}+$ normal TBI. According to the clinical guidelines, low ABI was defined as a value $\leq 0.9[16,17]$. For TBI, based on the guidelines we primarily explored a TBI cutoff of $\leq 0.7$ $[2,24]$. However, given limited evidence behind this threshold, we secondarily investigated a cutoff of $\leq 0.6$ based on prior literature [25].

We conducted a few sensitivity analyses. First, we stratified by several pre-specified demographic and clinical factors: age, gender, body mass index (BMI) $(<$ vs. $\geq 22 \mathrm{~kg} / \mathrm{m}^{2}$ ), diabetes status, and systolic blood pressure (< vs. $\geq 130 \mathrm{mmHg}$ ). The interactions of $\mathrm{ABI}$ and TBI categories with stratifying factors were evaluated by likelihood-ratio testing. Next, we restricted our analysis to 193 patients who had ABI and TBI measurements within two years prior to baseline, to minimize their misclassification due to changes over time. We also performed complete case analysis including all 247 patients in Models 1 and 2, 212 patients in Model 3, and 176 patients in Model 4. In all analyses, a $p$-value less than 0.05 was considered statistically significant. All statistical analyses were performed using Stata version 14 (Stata Corp, College Station, Texas, USA).

\section{Results}

Baseline characteristics

The mean age of the 247 patients was 66.8 (SD 11.6) years, and 167 were men (67.6\%). The median ABI and
TBI were 1.07 (IQI $0.91-1.17$ ) and 0.63 (0.5-0.76), respectively. The median elapsed time between ABI/TBI measurement and baseline was 0.69 (IQI 0.33-1.54) years. As shown in Fig. 1, ABI and TBI showed a moderate correlation $(r=0.57)$. Low ABI $(\leq 0.9)$ was observed in 58 patients $(23.5 \%)$, whereas $\mathrm{TBI} \leq 0.7$ and $\leq 0.6$ were observed in 163 (66.0\%) and 96 (38.9\%) patients, respectively. Patients with lower TBI were more likely to be older, have diabetes, and have a history of PAD and other CVD (Table 1). In contrast, there were no evident differences in BMI or hypertension. Patients with lower $\mathrm{ABI}$ were also likely to be older, have diabetes, and have a history of CVD (Supplementary File: Table S2).

\section{Independent associations of $\mathrm{ABI}$ and $\mathrm{TBI}$ with mortality} During a median follow-up of 5.2 (IQI 2.4-7.0) years, there were 116 deaths (47.0\%). Figure 2 shows the Kaplan-Meier curves for all-cause mortality according to ABI quartiles (Fig. 2a) and TBI quartiles (Fig. 2b). As expected, ABI showed a J-shaped pattern for all-cause mortality, with the lowest $\mathrm{ABI}$ quartile (ABI 0.31-0.91) having the worst prognosis and the highest quartile (ABI 1.18-1.41) demonstrating slightly worse prognosis than the second highest quartile (ABI 1.08-1.17). In contrast, lower TBI levels showed a potentially dose-response relationship to all-cause mortality, with its lowest quartile (TBI 0.18-0.50) showing the worst prognosis and the highest quartile (TBI 0.77-1.11) having the best prognosis. Similar results were found for both CVD mortality and non-CVD mortality (Supplementary File: Fig. S2).

Elevated mortality risk in the lowest ABI quartile, compared to second highest quartile, remained significant even after adjusting for demographic (Model 2) and clinical (Models 3 and 4) factors (Table 2). For example, the adjusted HR in Model 4 was 2.72 (95\% CI, 1.524.88). Although not significant, the highest quartile

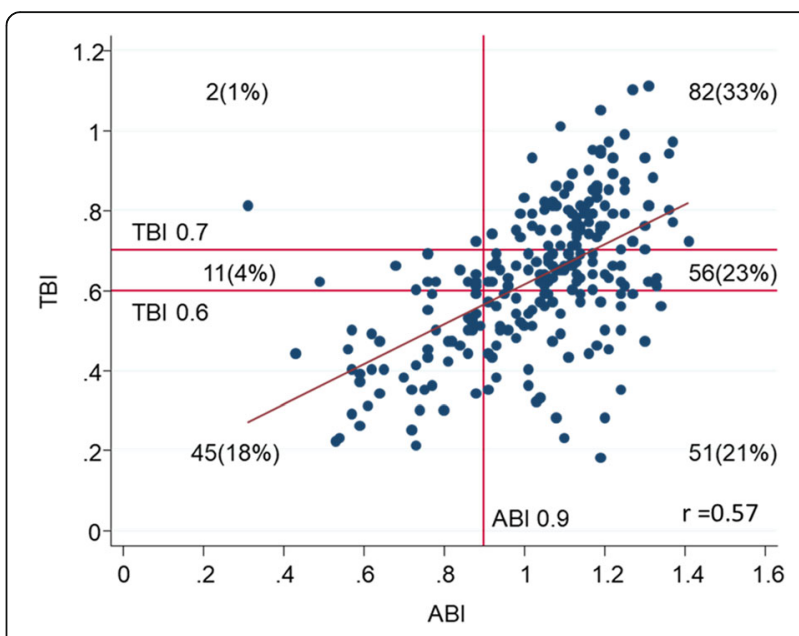

Fig. 1 Distribution and correlation of $A B \mid$ and $T B \mid$ 
Table 1 Baseline characteristics of patients stratified by TBI quartile

\begin{tabular}{|c|c|c|c|c|c|c|c|}
\hline \multirow[t]{3}{*}{ Characteristic } & \multicolumn{4}{|c|}{ Lower TBI (Quartile) } & \multirow{3}{*}{$\begin{array}{l}\text { Total } \\
(n=247)\end{array}$} & \multirow[t]{3}{*}{$P$-value } & \multirow{3}{*}{$\begin{array}{l}\text { Post } \\
\text { hoc }\end{array}$} \\
\hline & $\overline{Q 1}(0.18-0.50)$ & Q2 (0.51-0.63) & Q3 (0.64-0.76) & Q4 (0.77-1.11) & & & \\
\hline & $(n=63)$ & $(n=61)$ & $(n=65)$ & $(n=58)$ & & & \\
\hline Age (years) & $70.2 \pm 11.2$ & $68.6 \pm 11.2$ & $66.6 \pm 10.2$ & $61.5 \pm 12.4$ & $66.8 \pm 11.6$ & $<0.01$ & $c, e$ \\
\hline Hemodialysis vintage (year) & $7.6 \pm 6.9$ & $9.2 \pm 8.7$ & $11.3 \pm 8.9$ & $9.9 \pm 7.9$ & $9.5 \pm 8.2$ & 0.08 & \\
\hline Gender (male) (\%) & $46(73 \%)$ & $37(61 \%)$ & $42(65 \%)$ & $42(72 \%)$ & $167(68 \%)$ & 0.385 & \\
\hline Body mass index $\left(\mathrm{kg} / \mathrm{m}^{2}\right)$ & $21.8 \pm 3.6$ & $22.3 \pm 3.2$ & $22.1 \pm 3.9$ & $22.0 \pm 3.8$ & $22.1 \pm 3.6$ & 0.891 & \\
\hline \multicolumn{8}{|l|}{ History of smoking } \\
\hline Ever (\%) & $11(17 \%)$ & $11(18 \%)$ & $13(20 \%)$ & $16(28 \%)$ & $51(21 \%)$ & 0.504 & \\
\hline Never (\%) & $42(67 \%)$ & 39 (64\%) & $46(71 \%)$ & $34(59 \%)$ & $161(65 \%)$ & 0.557 & \\
\hline Unknown (\%) & $10(16 \%)$ & $11(18 \%)$ & $6(9 \%)$ & $8(14 \%)$ & $35(14 \%)$ & 0.534 & \\
\hline \multicolumn{8}{|l|}{ Comorbidity } \\
\hline Diabetes mellitus (\%) & $44(71 \%)$ & $31(52 \%)$ & $22(35 \%)$ & $18(32 \%)$ & $115(48 \%)$ & $<0.01$ & $b, c$ \\
\hline Hypertension (\%) & $40(69 \%)$ & $45(78 \%)$ & $44(72 \%)$ & $44(81 \%)$ & $173(75 \%)$ & 0.427 & \\
\hline Lipid metabolism disorder (\%) & $9(16 \%)$ & $9(16 \%)$ & $4(7 \%)$ & $4(8 \%)$ & $26(12 \%)$ & 0.246 & \\
\hline PAD (\%) & $55(87 \%)$ & $46(75 \%)$ & $49(75 \%)$ & $24(41 \%)$ & $174(70 \%)$ & $<0.01$ & $c, e, f$ \\
\hline Other CVDs (CAD, HF, stroke) (\%) & $51(81 \%)$ & $41(67 \%)$ & $39(60 \%)$ & $31(53 \%)$ & $162(66 \%)$ & $<0.01$ & c \\
\hline \multicolumn{8}{|l|}{ Primary kidney disease } \\
\hline Diabetic nephropathy (\%) & $43(68 \%)$ & $31(51 \%)$ & $20(31 \%)$ & $17(29 \%)$ & $111(45 \%)$ & $<0.01$ & $b, c$ \\
\hline Nephrosclerosis (\%) & $2(3 \%)$ & $3(5 \%)$ & $5(8 \%)$ & $6(10 \%)$ & $16(6 \%)$ & 0.4 & \\
\hline Chronic glomerulonephritis (\%) & $12(19 \%)$ & $13(21 \%)$ & $23(35 \%)$ & $17(29 \%)$ & $65(26 \%)$ & 0.138 & \\
\hline Polycystic kidney disease (\%) & $2(3 \%)$ & $2(3 \%)$ & $3(5 \%)$ & $3(5 \%)$ & $10(4 \%)$ & 0.929 & \\
\hline Other (\%) & $1(2 \%)$ & $7(11 \%)$ & $9(14 \%)$ & $6(10 \%)$ & $23(9 \%)$ & 0.092 & \\
\hline Unknown (\%) & $3(5 \%)$ & $5(8 \%)$ & $5(8 \%)$ & $9(16 \%)$ & $22(9 \%)$ & 0.204 & \\
\hline Systolic blood pressure $(\mathrm{mmHg})$ & $150 \pm 22$ & $151 \pm 25$ & $146 \pm 22$ & $147 \pm 23$ & $149 \pm 23$ & 0.551 & \\
\hline Diastolic blood pressure $(\mathrm{mmHg})$ & $77 \pm 11$ & $79 \pm 11$ & $82 \pm 11$ & $85 \pm 14$ & $81 \pm 12$ & $<0.01$ & $c, e$ \\
\hline Total cholesterol (mg/dl) & $163 \pm 38$ & $154 \pm 32$ & $155 \pm 30$ & $150 \pm 33$ & $156 \pm 33$ & 0.185 & \\
\hline \multicolumn{8}{|l|}{ Oral medication } \\
\hline Antihypertensive drugs (\%) & $37(59 \%)$ & $36(59 \%)$ & $35(54 \%)$ & $41(71 \%)$ & $149(60 \%)$ & 0.281 & \\
\hline Lipid-lowering drugs (\%) & $2(3 \%)$ & $4(7 \%)$ & $1(2 \%)$ & $1(2 \%)$ & $8(3 \%)$ & 0.37 & \\
\hline Hemoglobin (g/dl) & $10.6 \pm 1.2$ & $10.7 \pm 1.3$ & $10.6 \pm 1.3$ & $10.8 \pm 1.4$ & $10.7 \pm 1.3$ & 0.891 & \\
\hline Albumin $(g / d l)$ & $3.7 \pm 0.4$ & $3.6 \pm 0.3$ & $3.7 \pm 0.3$ & $3.8 \pm 0.3$ & $3.7 \pm 0.3$ & 0.231 & \\
\hline Calcium (mg/dl) & $8.5 \pm 0.6$ & $8.7 \pm 0.6$ & $8.9 \pm 0.7$ & $9.0 \pm 0.7$ & $8.8 \pm 0.7$ & $<0.01$ & $b, c, e$ \\
\hline Phosphate (mg/dl) & $5.0 \pm 1.6$ & $4.8 \pm 1.4$ & $4.8 \pm 1.3$ & $5.7 \pm 1.3$ & $5.1 \pm 1.4$ & $<0.01$ & $e, f$ \\
\hline$A B \mid$ & $0.85 \pm 0.22$ & $1.02 \pm 0.17$ & $1.09 \pm 0.13$ & $1.16 \pm 0.15$ & $1.03 \pm 0.20$ & $<0.01$ & $a, b, c, e$ \\
\hline
\end{tabular}

consistently demonstrated a $\mathrm{HR}>1$ in all models. In contrast, there was largely a dose-response association between TBI and mortality risk. In Model 1, even the second highest quartile with TBI 0.64-0.76 had significantly higher HR compared to the highest quartile (1.98 [95\% CI, 1.04-3.78]). The lowest and second lowest quartiles demonstrated significant and similar HRs across all four models (e.g., adjusted HR 2.63 [95\% CI, 1.36-5.12] and 2.89 [95\% CI, 1.49-5.61], respectively, in Model 4). The results were largely consistent for CVD mortality and non-CVD mortality (Supplementary File: Table S3), although HRs appeared greater for CVD 


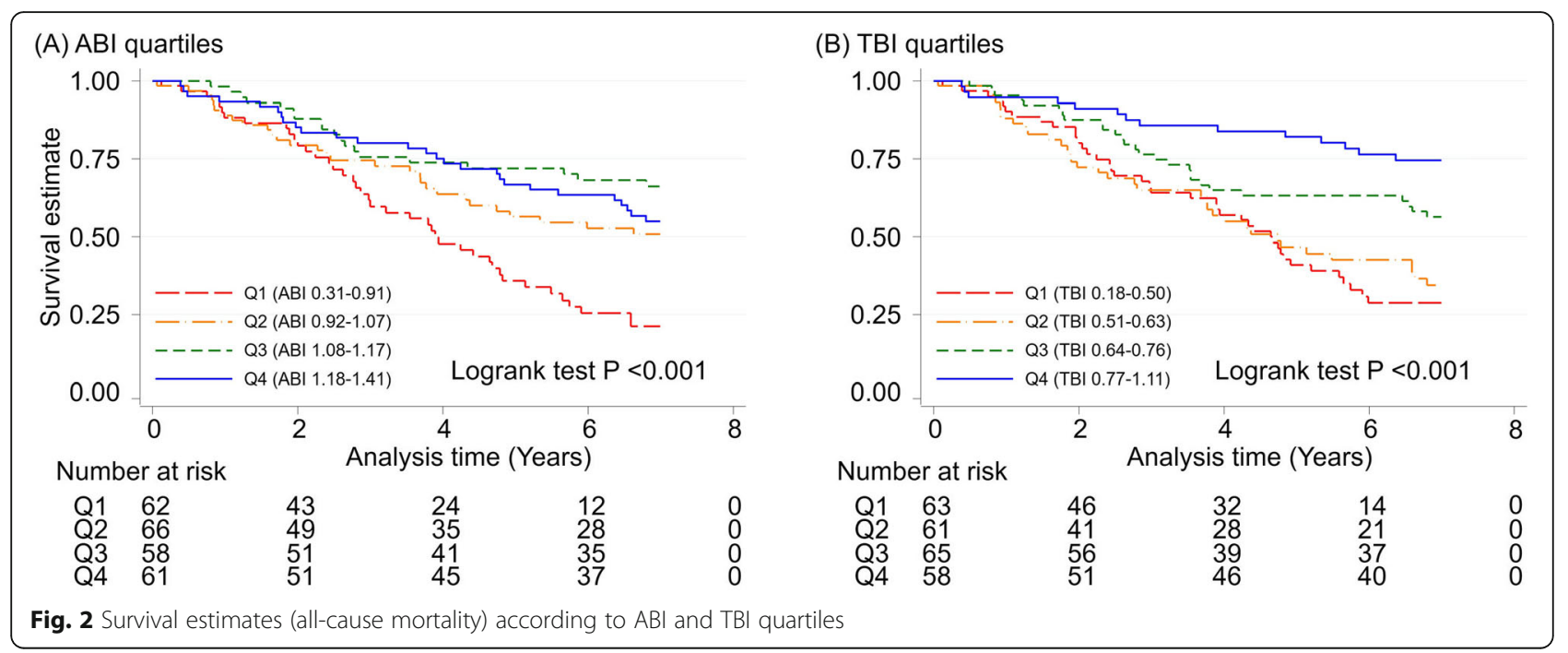

mortality than non-CVD mortality for both $\mathrm{ABI}$ and TBI. The exclusion of 12 patients with $\mathrm{ABI} \geq 1.4$ did not materially alter the results (Supplementary File: Table S4).

\section{Combined associations of $A B I$ and $T B I$ with mortality}

With TBI 0.7 as a threshold, there were 82 patients with normal/high $\mathrm{ABI}+$ normal $\mathrm{TBI}$ and 107 patients with normal/high ABI + low TBI. Corresponding numbers were 138 and 51 patients, respectively, when we used TBI 0.6 as a cutoff. Low ABI $(\leq 0.9)$ was seen in 58 patients, as noted above.

Figure 3 shows Kaplan-Meier curves for all-cause mortality according to the three categories of $\mathrm{ABI} / \mathrm{TBI}$ group, using TBI cutoffs of 0.7 (Fig. 3a) and 0.6 (Fig. 3b). The low ABI category $(\leq 0.9)$ (red line) showed the worst prognosis. Comparing the two TBI categories with nor$\mathrm{mal} /$ high $\mathrm{ABI}$, low TBI (orange line) showed worse prognosis than normal TBI (blue line), regardless of TBI threshold, although the separation of the two categories appeared more evident with TBI 0.6 as a threshold.

When we contrasted these three categories using Cox models, the low ABI category $(\leq 0.9)$ consistently demonstrated the highest HR in all models (Table 3). In those with normal/high ABI, low TBI showed significantly higher mortality compared to normal TBI in Model 1 regardless of TBI threshold (HR 1.94 [95\% CI, 1.20-3.13] with TBI 0.7 and 2.13 [95\% CI, 1.34-3.41] with TBI 0.6). However, the association was attenuated and no longer significant in Models 2-4 when TBI 0.7 was used as a threshold. In contrast, when low TBI was defined as $\leq 0.6$, normal/high ABI + low TBI had significantly higher

Table 2 HRs ( $95 \% \mathrm{Cl})$ of all-cause mortality (116 cases) according to ABI/TBI quartile

\begin{tabular}{|c|c|c|c|c|c|}
\hline$\overline{\mathrm{ABI}}$ & Q1 (0.31-0.91) & Q2 (0.92-1.07) & Q3 (1.08-1.17) & Q4 (1.18-1.41) & $\mathrm{P}$ for trend $(\mathrm{Q} 1-3)$ \\
\hline All-cause mortality & 41 deaths / 62 & 29 deaths / 66 & 19 deaths / 58 & 27 deaths / 61 & $(n=186)$ \\
\hline Model 1 & $3.15(1.82-5.44) * *$ & $1.67(0.94-2.98)$ & ref & $1.36(0.76-2.45)$ & $<0.001$ \\
\hline Model 2 & $2.99(1.72-5.19) * *$ & $1.69(0.94-3.01)$ & ref & $1.62(0.90-2.93)$ & $<0.001$ \\
\hline Model 3 & $2.83(1.60-5.03) * *$ & $1.54(0.86-2.78)$ & ref & $1.63(0.90-2.94)$ & $<0.001$ \\
\hline Model 4 & $2.72(1.52-4.88) * *$ & $1.45(0.79-2.64)$ & ref & $1.59(0.87-2.90)$ & $<0.001$ \\
\hline TBI & Q1 (0.18-0.50) & Q2 (0.51-0.63) & Q3 (0.64-0.76) & Q4 (0.77-1.11) & $\mathrm{P}$ for trend $(\mathrm{Q} 1-4)$ \\
\hline All-cause mortality & 40 deaths / 63 & 35 deaths / 61 & 27 deaths / 65 & 14 deaths / 58 & $(n=247)$ \\
\hline Model 1 & $3.91(2.12-7.21)^{* *}$ & $3.60(1.93-6.70) * *$ & $1.98(1.04-3.78) *$ & ref & $<0.001$ \\
\hline Model 2 & $2.74(1.47-5.11)^{* *}$ & $3.01(1.61-5.63) * *$ & $1.56(0.81-2.99)$ & ref & 0.001 \\
\hline Model 3 & $2.54(1.31-4.94) * *$ & $2.80(1.44-5.45) * *$ & $1.43(0.72-2.86)$ & ref & 0.004 \\
\hline Model 4 & $2.63(1.36-5.12) * *$ & $2.89(1.49-5.61) * *$ & $1.54(0.78-3.04)$ & ref & 0.004 \\
\hline
\end{tabular}

Model 1; unadjusted

Model 2; adjusted for age and gender

Model 3; Model 2+ diabetes mellitus, smoking status, history of cardiovascular disease, and hemodialysis vintage

Model 4; Model 3+ systolic blood pressure, total cholesterol, hemoglobin, albumin, calcium, and phosphate

${ }^{*} P<0.05$, ${ }^{*} P<0.01$ 
(A) TBI cutoff 0.7

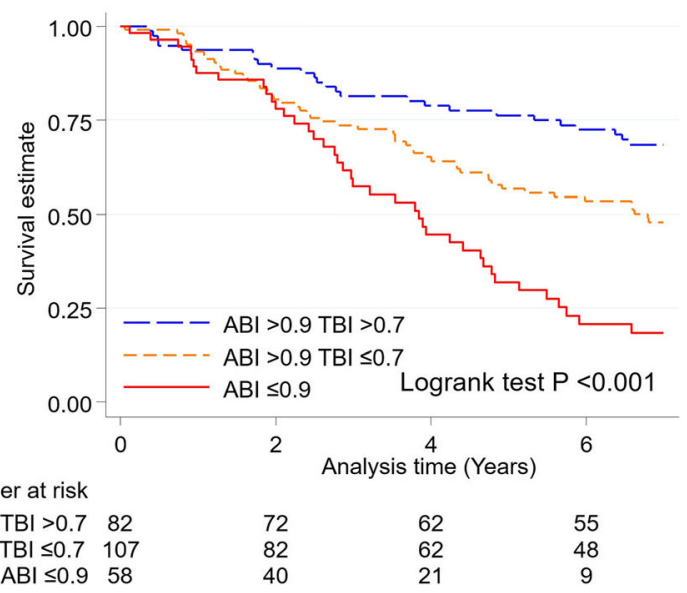

(B) TBI cutoff 0.6

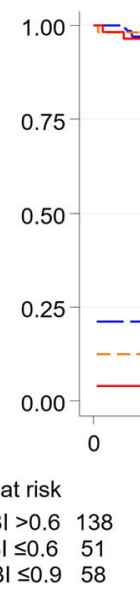

Number at risk $\mathrm{ABI}>0.9 \mathrm{~TB} \mid>0.6 \quad 138$ $\mathrm{AB}|>0.9 \mathrm{~TB}| \leq 0.6 \quad 51$ $\mathrm{ABI} \leq 0.958$

Fig. 3 Survival estimates (all-cause mortality) according to three categories of $A B|/ T B|$

mortality than normal/high ABI + normal TBI (HR 1.84 [95\% CI, 1.12-3.02] in Model 4). Consistent results were observed for CVD mortality and non-CVD mortality (Supplementary File: Fig. S3 and Table S5). Again, the results were largely similar after the exclusion of $\mathrm{ABI}$ $\geq 1.4$ (Supplementary File: Table S6).

\section{Sensitivity analysis}

The higher mortality risk for normal/high ABI + low TBI vs. normal/high $\mathrm{ABI}+$ normal TBI was mostly consistent across demographics and clinical subgroups tested (Fig. 4). The association was prominent in some subgroups (e.g., adjusted HR 3.82 [95\% CI, 1.35-10.86] in female and 2.58 [95\% CI, 1.24-5.39] in BMI $\geq 22$ ), although we did not observe statistically significant interactions. In 193 patients who had ABI and TBI measurements within two years prior to baseline, our findings were consistent (Supplementary File: Table S7 and S8). Finally, the results based on complete case analysis were similar to our main analysis (Supplementary File: Table S9 and S10).

\section{Discussion}

Among patients on hemodialysis, we confirmed a Jshaped association between $\mathrm{ABI}$ and mortality. In contrast, there was a potential dose-response relationship between TBI and mortality. These associations remained significant even after accounting for several potential

Table 3 HRs ( $95 \%$ Cl) of all-cause mortality (116 cases) according to three categories of ABI/TBI

\begin{tabular}{|c|c|c|c|}
\hline & $\mathrm{ABI}>0.9 \mathrm{TBI}>0.7$ & $\mathrm{ABI}>0.9 \mathrm{~TB} \mid \leq 0.7$ & $A B \mid \leq 0.9$ \\
\hline All-cause mortality & 25 deaths / 82 & 51 deaths / 107 & 40 deaths / 58 \\
\hline Model 1 & ref & $1.94(1.20-3.13) * *$ & $3.84(2.32-6.37) * *$ \\
\hline Model 2 & ref & $1.60(0.99-2.61)$ & $2.89(1.72-4.86) * *$ \\
\hline Model 3 & ref & $1.48(0.89-2.47)$ & $2.75(1.57-4.82) * *$ \\
\hline \multirow[t]{2}{*}{ Model 4} & ref & $1.65(0.98-2.77)$ & $2.88(1.62-5.12) * *$ \\
\hline & $\mathrm{ABI}>0.9 \mathrm{~TB} \mid>0.6$ & $\mathrm{ABI}>0.9 \mathrm{~TB} \mid \leq 0.6$ & $A B \mid \leq 0.9$ \\
\hline All-cause mortality & 48 deaths / 138 & 28 deaths / 51 & 40 deaths / 58 \\
\hline Model 1 & ref & $2.13(1.34-3.41) * *$ & $3.23(2.11-4.95) * *$ \\
\hline Model 2 & ref & $1.97(1.23-3.15)^{* *}$ & $2.64(1.71-4.08) * *$ \\
\hline Model 3 & ref & $1.89(1.16-3.06)$ * & $2.63(1.65-4.17) * *$ \\
\hline Model 4 & ref & $1.84(1.12-3.02) *$ & $2.53(1.56-4.11) * *$ \\
\hline
\end{tabular}

Model 1; unadjusted

Model 2; adjusted for age and gender

Model 3; Model 2+ diabetes mellitus, smoking status, history of cardiovascular disease, and hemodialysis vintage

Model 4; Model 3+ systolic blood pressure, total cholesterol, hemoglobin, albumin, calcium, and phosphate

${ }^{*} P<0.05,{ }^{*} P<0.01$ 


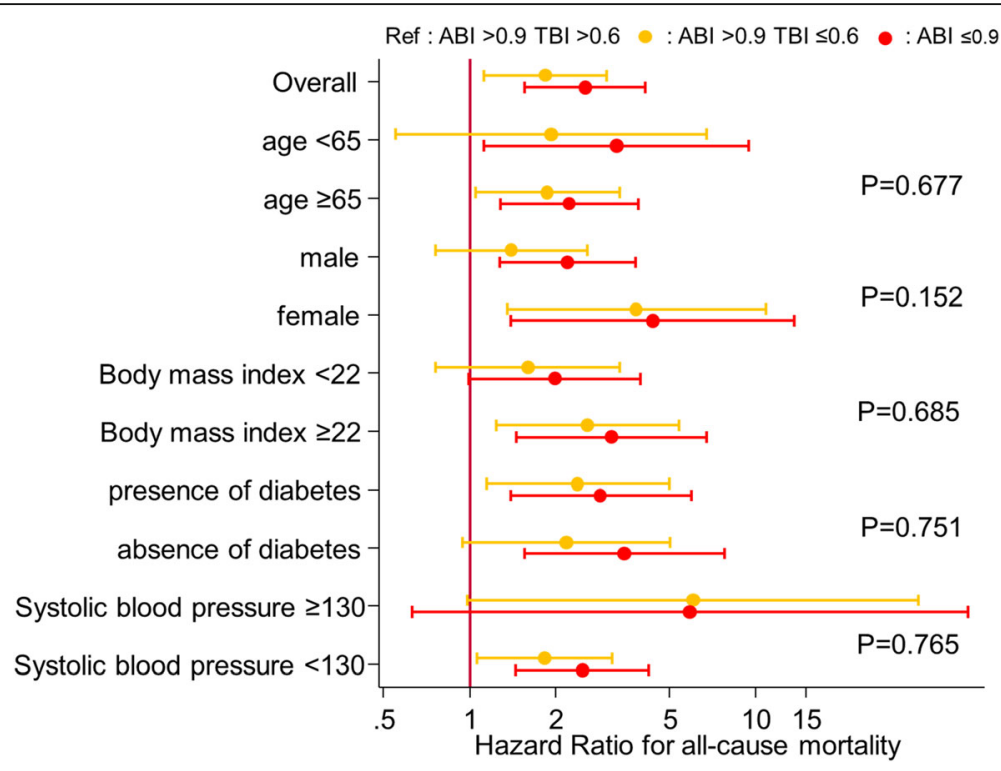

Fig. $4 \mathrm{HR}(95 \% \mathrm{Cl})$ of all-cause mortality according to "normal" or "low" ABI/TBI in subgroups. Adjusted for age, gender, diabetes mellitus, smoking status, history of cardiovascular disease, hemodialysis vintage, systolic blood pressure, total cholesterol, hemoglobin, albumin, calcium, and phosphate. The $P$ values represent significance levels for interaction terms

confounders, with HRs of all-cause mortality for the lowest $\mathrm{ABI}$ and TBI quartiles (vs. respective reference category) ranging from $\sim 2$ to $\sim 4$ depending on models. Among patients with normal/high ABI, low TBI vs. normal TBI demonstrated poorer prognosis, with an unadjusted $H R \sim 2$. This pattern remained consistent even after accounting for potential confounders when TBI 0.6 was used as a threshold of low TBI. These results were largely consistent when we explored CVD and non-CVD mortality as outcomes. The elevated mortality risk in low TBI vs. normal TBI among those with normal/high ABI was consistent across several subgroups, although the association was especially evident in females and those with $\mathrm{BMI} \geq 22$.

The TBI-mortality relationship in our study is consistent with a few previous studies. Nonetheless, to the best of our knowledge, this is the largest study with data on TBI in hemodialysis patients. We uniquely observed that the additional prognostic value of low TBI within individuals with normal/high $\mathrm{ABI}$. In addition, this is the first study reporting the prognostic value of TBI from Asia. Since the CVD risk profiles are different between Asians and other racial groups [26], and Asians are the largest racial group migrating to Europe and North America [27], our results may have increasing relevance globally.

Of note, the additional prognostic value of low TBI in normal/high ABI was consistent across key subgroups, although non-significantly more evident in females and patients with higher BMI than their counterparts. Nonetheless, we conducted subgroup analyses without a prespecified hypothesis, and thus the results should be interpreted carefully. Also, we need to acknowledge limited power in this subgroup analysis. Therefore, future larger studies are needed to confirm our observations.

Potential reasons behind the prognostic value of TBI beyond ABI warrant discussion. This may be due to the fact that TBI reflects leg ischemia better than $A B I$ in persons with arterial calcification [28]. Since medial arterial calcification is highly prevalent in the hemodialysis and diabetic population, TBI can be an especially useful prognostic marker in these populations [29]. Another possibility is that, theoretically, TBI can capture arterial stenosis above and below the ankles while ABI reflects only stenosis above the ankles. Thus, TBI may more comprehensively represent overall leg ischemia compared to ABI. However, TBI has been rarely researched in a large dataset, and thus will require further investigation.

Our findings have several important clinical and research implications. Although clinical guidelines currently recommend measuring TBI only in individuals with $\mathrm{ABI}>1.4$, the independent prognostic value of $\mathrm{ABI}$ and TBI indicates the usefulness to simultaneously measure $\mathrm{ABI}$ and $\mathrm{TBI}$ even among those with normal ABI. The additional time to measure TBI after ABI is < $5 \mathrm{~min}$, and thus it seems worth considering this approach, at least in patients on hemodialysis. As noted above, a few major clinical guidelines recommend 0.7 as the threshold of TBI. However, the evidence behind this recommendation is not necessarily robust. In this context, our results support 0.6 over 0.7 in terms of classifying the 
mortality risk among persons with normal/high ABI. Interestingly, our observation is consistent with a previous study reporting $\mathrm{TBI} \leq 0.6$ as a reasonable threshold to identify hemodialysis patients with PAD [30].

There are some other limitations in our study. First, $\mathrm{ABI}$ and TBI were measured during hemodialysis therapy. Hemodynamic changes during hemodialysis therapy may have affected the $\mathrm{ABI}$ and TBI measurements. However, the ABI and TBI are determined by the ratios of blood pressure in the ankle and toe, respectively, relative to arm blood pressure, with the blood pressures usually obtained contemporaneously. Therefore, any effect of systemic hemodynamic change on the ABI and TBI is likely to be smaller than the effect on each of brachial, ankle, and toe blood pressures. Second, the analysis is based on a single measurement of $\mathrm{ABI}$ and $\mathrm{TBI}$ which is prone to non-differential misclassification. Nonetheless, such a misclassification usually biases results towards the null. Third, the measurement of $\mathrm{ABI}$ and TBI was based on clinical indication, and thus the generalizability of our results should be carefully evaluated. Fourth, we did not have information on leg vascular procedures and thus cannot infer whether the interpretation of ABI and TBI should be different before and after leg revascularization. Finally, there is the possibility of residual confounding (unmeasured covariates such as parathyroid hormone and triglycerides or unknown confounding).

\section{Conclusions}

In conclusion, among maintenance hemodialysis patients, in contrast to a J-shaped association for ABI, TBI showed a robust and independent dose-response association with mortality. Moreover, TBI classified the risk of mortality in hemodialysis patients with normal/high ABI. Our results support the importance of evaluating TBI in addition to ABI in this clinical population.

\section{Supplementary information}

Supplementary information accompanies this paper at https://doi.org/10. 1186/s12882-020-01991-7.

\section{Additional file 1}

\section{Abbreviations}

TBI: Toe-brachial index; ABI: Ankle-brachial index; PAD: Peripheral artery disease; CKD: Chronic kidney disease; CVD: Cardiovascular disease; CAD: Coronary artery disease; HF: Heart failure; HR: Hazard ratios; BMI: Body mass index; IQI: Inter quartile interval

\section{Acknowledgements}

We acknowledge the support provided by the following investigators and members of Kaikoukai Healthcare Group, who participated in this study: Hachiro Seno, Hiroshi Sakurai, Masao Matsuzawa, Haruka Goto, Yumie Kawagoe.

\section{Authors' contributions}

M.H. collected the data and contributed to data analysis and interpretation as well as drafting the manuscript. T.I. and M.O. contributed to data collection, analysis and interpretation. J.I. and S.M. contributed to data analysis and interpretation. S.A. and H.K. contributed to data collection. S.M. conceptualized the cohort and contributed to data collection. K.M. designed the present study, contributed to data interpretation and drafting manuscript, and provided critical feedback on the manuscript as well as supervision and approved the final version of the manuscript for publication. All authors were involved in editing and reviewing the manuscript. The authors read and approved the final manuscript.

\section{Funding}

The Kaikoukai Healthcare Group partially supported this study. The authors used clinical data collected by this Group. The Group was not involved in study design, data analysis, or interpretation.

\section{Availability of data and materials}

The data that support the findings of this study are available from Nagoya university, but restrictions apply to the availability of these data, which were used under license for the current study, and so are not publicly available. Data are however available from the authors upon reasonable request and with permission of Nagoya university.

\section{Ethics approval and consent to participate}

In this study, we followed the Japanese Ministry of Health, Labor, and Welfare's "Outline of ethical guidelines for medical and health research involving human subjects" (issued on December 22, 2014 and revised on February 28, 2017) and the Helsinki Declaration (revised 2013). The study protocol was approved by the Institutional Review Boards of both Nagoya University and the Kaikoukai Healthcare Group (IRB 2014-0422).

\section{Consent for publication}

As this was a retrospective cohort study, the need for informed consent was waived by the Institutional Review Boards.

\section{Competing interests}

S.M. is supported by Otsuka Pharmaceutical Co.,Ltd., Chugai Pharmaceutical Co.,Ltd., Pfizer Inc., Kyowa Hakko Kirin Co.,Ltd., MSD KK, Astellas Pharma Inc., Torii Pharmaceutical Co.,Ltd., Daiichi Sankyo Co.,Ltd., Sumitomo Dainippon Pharma Co.,Ltd., Alexion Pharmaceuticals,Inc., and Sanwa Kagaku Kenkyusho Co.,Ltd. None of these companies were involved in study design, data collection, analysis and interpretation of data, writing of the report, or decision to submit the article for publication. K.M. received funding and personal fee from Kyowa Kirin and Fukuda Denshi and personal fee from Akebia outside of the submitted work. All other authors declare no potential conflicts of interest.

\section{Author details}

'Department of Epidemiology, Johns Hopkins Bloomberg School of Public Health, 2024 E. Monument Street, Suite 2-600, Baltimore, MD 21287, USA.

${ }^{2}$ Department of Nephrology, Graduate School of Medicine, Nagoya University, Nagoya, Japan. ${ }^{3}$ Division of Nephrology, Department of Medicine, Johns Hopkins University School of Medicine, Baltimore, MD 21287, USA.

${ }^{4}$ Kaikoukai Healthcare Group Kaikoukai Central Clinic, Nagoya, Japan.

Received: 10 February 2020 Accepted: 29 July 2020

Published online: 20 August 2020

\section{References}

1. O'Hare AM, Bertenthal D, Shlipak MG, Sen S, Chren MM. Impact of renal insufficiency on mortality in advanced lower extremity peripheral arterial disease. J Am Soc Nephrol. 2005;16(2):514-9.

2. Conte MS, Bradbury AW, Kolh P, White JV, Dick F, Fitridge R, Mills JL, Ricco $J B$, Suresh KR, Murad MH, et al. Global Vascular Guidelines on the Management of Chronic Limb-Threatening Ischemia. Eur J Vasc Endovasc Surg. 2019;58(1 s):S1-S109 e133.

3. Wattanakit K, Folsom AR, Selvin E, Coresh J, Hirsch AT, Weatherley BD. Kidney function and risk of peripheral arterial disease: results from the atherosclerosis risk in communities (ARIC) study. J Am Soc Nephrol. 2007; 18(2):629-36. 
4. Matsushita K, Ballew SH, Coresh J, Arima H, Arnlov J, Cirillo M, Ebert N, Hiramoto JS, Kimm H, Shlipak MG, et al. Measures of chronic kidney disease and risk of incident peripheral artery disease: a collaborative meta-analysis of individual participant data. Lancet Diabetes Endocrinol. 2017:5(9):718-28.

5. O'Hare AM, Glidden DV, Fox CS, Hsu CY. High prevalence of peripheral arterial disease in persons with renal insufficiency: results from the National Health and nutrition examination survey 1999-2000. Circulation. 2004;109(3):320-3.

6. 2018 USRDS annual data report: Chapter 4: Cardiovascular Disease in Patients with CKD. https://www.usrds.org/adr.aspx.. Accessed 24 Oct 2019.

7. Conte MS, Pomposelli FB, Clair DG, Geraghty PJ, McKinsey JF, Mills JL, Moneta GL, Murad MH, Powell RJ, Reed AB, et al. Society for Vascular Surgery practice guidelines for atherosclerotic occlusive disease of the lower extremities: management of asymptomatic disease and claudication. J Vasc Surg. 2015;61(3 Suppl):2s-41s.

8. Tendera M, Aboyans V, Bartelink ML, Baumgartner I, Clement D, Collet JP, Cremonesi A, De Carlo M, Erbel R, Fowkes FG, et al. ESC Guidelines on the diagnosis and treatment of peripheral artery diseases: Document covering atherosclerotic disease of extracranial carotid and vertebral, mesenteric, renal, upper and lower extremity arteries: the Task Force on the Diagnosis and Treatment of Peripheral Artery Diseases of the European Society of Cardiology (ESC). Eur Heart J. 2011;32(22):2851-906.

9. Suominen $V$, Uurto I, Saarinen J, Venermo M, Salenius J. PAD as a risk factor for mortality among patients with elevated ABI--a clinical study. Eur J Vasc Endovasc Surg. 2010;39(3):316-22

10. Potier L, Halbron M, Bouilloud F, Dadon M, Le Doeuff J, Ha Van G, Grimaldi A, Hartemann-Heurtier A. Ankle-to-brachial ratio index underestimates the prevalence of peripheral occlusive disease in diabetic patients at high risk for arterial disease. Diabetes Care. 2009;32(4):e44.

11. Fowkes FG, Murray GD, Butcher I, Heald CL, Lee RJ, Chambless LE, Folsom AR, Hirsch AT, Dramaix M, de Backer $G$, et al. Ankle brachial index combined with Framingham risk score to predict cardiovascular events and mortality: a meta-analysis. Jama. 2008;300(2):197-208.

12. Resnick HE, Lindsay RS, McDermott MM, Devereux RB, Jones KL, Fabsitz RR, Howard BV. Relationship of high and low ankle brachial index to all-cause and cardiovascular disease mortality: the strong heart study. Circulation. 2004;109(6):733-9.

13. Emanuele MA, Buchanan BJ, Abraira C. Elevated leg systolic pressures and arterial calcification in diabetic occlusive vascular disease. Diabetes Care. 1981;4(2):289-92.

14. Cozzolino M, Mazzaferro S, Pugliese F, Brancaccio D. Vascular calcification and uremia: what do we know? Am J Nephrol. 2008;28(2):339-46.

15. Everhart JE, Pettitt DJ, Knowler WC, Rose FA, Bennett PH. Medial arterial calcification and its association with mortality and complications of diabetes. Diabetologia. 1988;31(1):16-23.

16. Gerhard-Herman MD, Gornik HL, Barrett C, Barshes NR, Corriere MA, Drachman DE, Fleisher LA, Fowkes FGR, Hamburg NM, Kinlay S, et al. 2016 AHA/ACC guideline on the Management of Patients with Lower Extremity Peripheral Artery Disease: executive summary: a report of the American College of Cardiology/American Heart Association task force on clinical practice guidelines. J Am Coll Cardiol. 2017;69(11):1465-508.

17. Halliday A, Bax JJ. The 2017 ESC guidelines on the diagnosis and treatment of peripheral arterial diseases, in collaboration with the European Society for Vascular Surgery (ESVS). Eur J Vasc Endovasc Surg. 2018;55(3):301-2.

18. Hyun S, Forbang NI, Allison MA, Denenberg JO, Criqui MH, Ix JH. Anklebrachial index, toe-brachial index, and cardiovascular mortality in persons with and without diabetes mellitus. J Vasc Surg. 2014;60(2):390-5.

19. Thejas PK, Ritika P, Matthew AA, Michael CC, Joachim HI, Dena ER, Pranav SG. Association of Ankle-Brachial and toe-Brachial Indexes with Mortality in patients with CKD. Kidney Med. 2020;2(1):68-75.

20. Prasad R, Kamath T, Ginsberg C, Potok OA, Ix JH, Garimella PS, Rifkin DE. The association of the ankle-brachial index, the toe-brachial index, and their difference, with mortality and limb outcomes in dialysis patients. Hemodial Int. 2019;23(2):214-22.

21. Kalim S, Trottier CA, Wenger JB, Wibecan J, Ahmed R, Ankers E, Karumanchi SA, Thadhani R, Berg AH. Longitudinal changes in protein Carbamylation and mortality risk after initiation of hemodialysis. Clin J Am Soc Nephrol. 2016;11(10):1809-16.

22. Banerjee T, Kim SJ, Astor B, Shafi T, Coresh J, Powe NR. Vascular access type, inflammatory markers, and mortality in incident hemodialysis patients: the choices for healthy outcomes in caring for end-stage renal disease (CHOICE) study. Am J Kidney Dis. 2014;64(6):954-61.
23. Kontopantelis E, White IR, Sperrin M, Buchan I. Outcome-sensitive multiple imputation: a simulation study. BMC Med Res Methodol. 2017;17(1):2.

24. Norgren L, Hiatt WR, Dormandy JA, Nehler MR, Harris KA, Fowkes FG. InterSociety Consensus for the Management of Peripheral Arterial Disease (TASC II). J Vasc Surg. 2007;45 Suppl S:S5-67.

25. Morimoto S, Nakajima F, Yurugi T, Morita T, Jo F, Nishikawa M, Iwasaka T, Maki K. Risk factors of normal ankle-brachial index and low toe-brachial index in hemodialysis patients. Ther Apheresis Dial. 2009;13(2):103-7.

26. Tanaka K, Watanabe T, Takeuchi A, Ohashi Y, Nitta K, Akizawa T, Matsuo S, Imai E, Makino H, Hishida A. Cardiovascular events and death in Japanese patients with chronic kidney disease. Kidney Int. 2017;91(1):227-34.

27. Asian alone or in combination with one or more other races: 2017 American Community Survey 1-Year Estimates. https://data.census.gov/ cedsci/table?q=Asian\%20alone\%20or\%20in\%20combination\%20with\%2 0one\%20or\%20more\%20other\%20races\&hidePreview=false\&tid=ACSDT1Y2 016.B02011\&vintage=2017. Accessed 24 Oct 2019.

28. Norgren L, Hiatt WR, Dormandy JA, Nehler MR, Harris KA, Fowkes FG, Bell K, Caporusso J, Durand-Zaleski I, Komori K, et al. Inter-society consensus for the Management of Peripheral Arterial Disease (TASC II). Eur J VasC Endovasc Surg. 2007;33(Suppl 1):S1-75.

29. Young MJ, Adams JE, Anderson GF, Boulton AJ, Cavanagh PR. Medial arterial calcification in the feet of diabetic patients and matched non-diabetic control subjects. Diabetologia. 1993;36(7):615-21.

30. Matsuzawa R, Aoyama N, Yoshida A. Clinical characteristics of patients on hemodialysis with peripheral arterial disease. Angiology. 2015;66(10):911-7.

\section{Publisher's Note}

Springer Nature remains neutral with regard to jurisdictional claims in published maps and institutional affiliations.
Ready to submit your research? Choose BMC and benefit from:

- fast, convenient online submission

- thorough peer review by experienced researchers in your field

- rapid publication on acceptance

- support for research data, including large and complex data types

- gold Open Access which fosters wider collaboration and increased citations

- maximum visibility for your research: over $100 \mathrm{M}$ website views per year

At BMC, research is always in progress.

Learn more biomedcentral.com/submissions 